\title{
Corrosion Characteristics of Copper in Malaysian Bioethanol and Gasoline blends
}

\author{
T. Saravana Kannan ${ }^{1, a}$, C. Piraiarasi ${ }^{1, b}$, Abu Saleh Ahmed ${ }^{2, c}$, F.N. Ani ${ }^{3, d}$ \\ ${ }^{1}$ Faculty of Engineering, Computing and Science, Swinburne University of Technology, Kuching, \\ Sarawak, Malaysia \\ ${ }^{2}$ Department of Mechanical and Manufacturing Engineering, Faculty of Engineering, Universiti \\ Malaysia Sarawak, Sarawak, Malaysia \\ ${ }^{3}$ Faculty of Mechanical Engineering, Universiti Teknologi Malaysia, Skudai, Johor D.T., Malaysia \\ asthangavelu@swinburne.edu.my, bpchelladorai@swinburne.edu.my, ${ }^{\mathrm{c}}$ aasaleh@feng.unimas.my, \\ dfarid@fkm.utm.my
}

Keywords: Corrosion; Bioethanol; Gasoline; Copper

\begin{abstract}
The present study aims to investigate the corrosion characteristics of copper commonly encountered in the spark ignition (SI) engine fuel system with Malaysian bioethanol and gasoline blends. Static immersion tests in E0 (gasoline), E10 and E85 were carried out at room temperature for $1320 \mathrm{~h}$. Mechanical, physical and chemical properties of copper was investigated before and after immersion tests. Investigations were carried out on change in morphological properties using optical microscope; change in chemical structure using FTIR; change in mass and volume by weight loss measurement; hardness changes using universal hardness tester; and change of chemical properties of the fuel blends using total acid number titration method. The test results showed that corrosion of copper was increased with the high concentration of ethanol in the blends.
\end{abstract}

\section{Introduction}

Biofuels (bioethanol and biodiesel) has gained progressive importance as alternative fuel for automobiles because they can significantly reduce environmental pollution and dependence on fossil fuel [1]. Bioethanol represent an important renewable fuel for gasoline engines without any engine modification to replace the usage of fossil fuels [2]. However, changes in the fuel composition and the introduction of alternative fuels often create material compatibility issues in terms of corrosion and the degradation of the automobile parts.

The presence of water and oxygen content in the ethanol will contribute to degradation in the automobile parts of the fuel system in the form of corrosion [3]. In gasoline engines, fuel comes into contact with a wide variety of engine parts including fuel pump, gaskets, fuel injector, filters, carburetor, fuel liners, bearing, piston, piston rings, etc. Among them, copper alloy based parts like fuel pump; bearing, bushing, etc. are mostly affected by the fuel [4]. These may give rise to potential problems such as interaction with metal surfaces and at the same time, degradation of fuel properties.

It has been suggested that copper, aluminum, zinc, brass and bronze are not compatible with biodiesel [4-6, 13]. Very limited research is found the corrosion behavior of copper and its alloy in bioethanol and gasoline blends [7]. The objective of this research to investigate the corrosion characteristics of Copper in Malaysian Bioethanol and Gasoline blends to find the suitability of bioethanol for Malaysia vehicles.

\section{Materials and Methods}

The test specimen of copper (40 mm length $\times 25 \mathrm{~mm}$ width $\times 3 \mathrm{~mm}$ thickness) as in Fig. $1 \mathrm{~A}$ and B were made from flat plate by machining and grinding. For hanging the specimen into fuels, a hole of diameter $3.5 \mathrm{~mm}$ was drilled near the edge of the specimen. The test bioethanol was prepared by mixing $80 \%$ lab grade denatured commercial ethanol and $20 \%$ bioethanol produced from sago bark 